\title{
Synthesis of Sulfonated Poly(1,4-diphenoxybenzene) for Proton Exchange Membrane
}

\author{
Kazuya Matsumoto, Shinji Ando, and Misuru UEDA ${ }^{\dagger}$ \\ Department of Organic and Polymeric Materials, Graduate School of Science and Engineering, \\ Tokyo Institute of Technology, 2-12-1 Ookayama, Meguro-ku, Tokyo 152-8552, Japan
}

(Received April 23, 2007; Accepted May 9, 2007; Published June 19, 2007)

\begin{abstract}
KEY WORDS Sulfonated Poly(1,4-diphenoxybenzene) / Proton Exchange Membrane / Polyphenylene / Oxidative Coupling Polymerization / Proton Conductivity / [doi:10.1295/polymj.PJ2007018]
\end{abstract}

Recently, proton exchange membranes (PEM) have attracted much attention due to their great promise for applications such as automotive, stationary, and portable power, where Nafion and sulfonated aromatic polymers such as, poly(ether sulfone)s, poly(ether ketone)s, polyimides, and poly(phenylene ether) containing sulfonic acids have been extensively studied. ${ }^{1,2}$ However, durability of those sulfonated aromatic membranes in fuel cells is not high because of hydrolytic and oxidative degradation. Quite recently, sulfonated polyphenylenes (PPs) have been reported to show excellent thermochemical stability because of no heteroatom in the main chains. ${ }^{3-5}$ These PPs are prepared by the nickel-catalyzed coupling of aromatic halides in the presence of zinc and Diels-Alder polymerization of 1,4-bis(2,4,5-triphenylcyclopentadienone)benzene and di(ethynyl)benzene. Their synthesis requires a tedious multi-step procedure, and more straightforward method is necessary to prepare PPs. In previous papers, ${ }^{6,7}$ we reported a facile synthesis of poly(2,5-di- $n$-butoxyphenylene) by oxidative coupling polymerization of 1,4-di-n-butoxybenzene using $\mathrm{FeCl}_{3}$ as an oxidant. To expand the preparative utility of this method, we applied this method to oxidative coupling polymerization of 1,4-diphenoxybenzene (1), and the resulting poly(1,4-diphenoxybenzene) easily underwent sulfonation, giving the sulfonated PPs.

This paper describes a successful synthesis and characterization of poly(1,4-diphenoxybenzene) (2) by oxidative coupling polymerization of $\mathbf{1}$ using $\mathrm{FeCl}_{3}$, and the proton conductivity of sulfonated poly(1,4-diphenoxybenzene) (4).

\section{EXPERIMENTAL}

\section{Materials}

Nitrobenzene was purified by washing sequentially with diluted aqueous $\mathrm{HCl}$, water, aqueous $\mathrm{NaOH}$, and water followed by drying over $\mathrm{CaCl}_{2}$ and distillation. Dichloromethane was purified by vacuum distillation from calcium hydride. Reagent grade anhydrous $\mathrm{FeCl}_{3}$ and 1,4-diphenoxybenzene (1) were used as received.

\section{Preparation of Poly (1,4-diphenoxyphenylene) (2)}

To a solution of $\mathbf{1}(2.10 \mathrm{~g}, 8 \mathrm{mmol})$ in nitrobenzene $(14 \mathrm{~mL})$ was added $\mathrm{FeCl}_{3}(5.19 \mathrm{~g}, 32 \mathrm{mmol})$ with stirring vigorously at room temperature under nitrogen. The solution was stirred at $40^{\circ} \mathrm{C}$ for $24 \mathrm{~h}$, and poured into methanol containing a small amount of concentrated $\mathrm{HCl}$. The precipitate was filtered and washed with methanol. It was dissolved in dichloromethane, filtered and reprecipitated with ethyl acetate. The precipitate was collected and dried at $120^{\circ} \mathrm{C}$ for $8 \mathrm{~h}$ under reduced pressure. The yield was $1.42 \mathrm{~g}(68 \%)$. IR (KBr, v); 1215 (C-O-C), 690, 1489, $1593 \mathrm{~cm}^{-1}$ $(\mathrm{Ph})$. Anal. $\left(\mathrm{C}_{18} \mathrm{H}_{12} \mathrm{O}_{2}\right)$ : Calcd: $\mathrm{C}, 83.06 \%$; $\mathrm{H}, 4.65 \%$; Found: C, $83.28 \%$; H, $4.28 \%$.

Model Compound. p-Phenylenedioxybis(4-benzenesulfonic acid) (3)

To a solution of $\mathbf{1}(1.05 \mathrm{~g}, 4 \mathrm{mmol})$ in dichloromethane $(32 \mathrm{~mL})$, a solution of chlorosulfonic acid $(0.53$ $\mathrm{mL}, 8 \mathrm{mmol})$ in dichloromethane $(3.2 \mathrm{~mL})$ was slowly added with stirring at room temperature under nitrogen. The mixture was stirred for $16 \mathrm{~h}$ at room temperature. The solid was filtered, washed with dichloromethane, and dried at room temperature for $1 \mathrm{~d}$ under the reduced pressure. The yield was $1.48 \mathrm{~g}(88 \%)$. IR ( $\mathrm{KBr}$, v); 1184 (-SO3H), 1246 (C-O-C), 683, 1496, 1593 $\mathrm{cm}^{-1}(\mathrm{Ph}) .{ }^{1} \mathrm{H}$ NMR (DMSO- $\left.d_{6}, \delta, \mathrm{ppm}\right): 6.96(\mathrm{~d}$, 4H), $7.06(\mathrm{~s}, 4 \mathrm{H}), 7.67$ (d, 4H). ${ }^{13} \mathrm{C}$ NMR (DMSO- $d_{6}, \delta$, ppm): 117.27, 120.73, 127.64, 141.57, 152.21, 158.05. Anal. $\left(\mathrm{C}_{18} \mathrm{H}_{12} \mathrm{Na}_{2} \mathrm{O}_{8} \mathrm{~S}_{2}\right)$ (Sodium salt of 3 ): Calcd: $\mathrm{C}$, $46.35 \%$; H, 2.59\%; Found: C, 46.55\%; H, 2.82\%.

${ }^{\dagger}$ To whom correspondence should be addressed (Tel/Fax: +81-3-5734-2127, E-mail: ueda.m.ad@m.titech.ac.jp). 
Sulfonated Poly (1,4-diphenoxyphenylene) (4)

To a solution of polymer $2(0.13 \mathrm{~g}, 0.5 \mathrm{mmol})$ in dichloromethane $(2 \mathrm{~mL})$, a solution of chlorosulfonic acid $(0.13 \mathrm{~mL}, 2 \mathrm{mmol})$ in dichloromethane $(0.8 \mathrm{~mL})$ was slowly added with stirring under nitrogen. The mixture was stirred at room temperature for $24 \mathrm{~h}$, and then poured into hexane. The precipitate was collected by filtration and stirred in hot toluene. The precipitate was collected and washed with toluene and hexane. It was dried at $100^{\circ} \mathrm{C}$ for $8 \mathrm{~h}$ under the reduced pressure to give the fully sulfonated polymer 4a. The yield was $0.19 \mathrm{~g}(90 \%)$. IR $(\mathrm{KBr}, v) ; 1184$ $\left(-\mathrm{SO}_{3} \mathrm{H}\right), 1223$ (C-O-C), 690, 1493, $1601 \mathrm{~cm}^{-1}(\mathrm{Ph})$. The partially sulfonated polymers $\mathbf{4 b}$ and $\mathbf{4 c}$ were prepared by using $1.00(0.07 \mathrm{~mL})$ and $0.5(0.03 \mathrm{~mL})$ mmol of chlorosulfonic acid, respectively in the similar conditions described above. The numbers of sulfonic acid groups in the repeating unit of $\mathbf{4 b}$ and $4 c$ were 0.74 and 0.38 , respectively. Ion exchange capacity (IEC) was determined by titration with $0.02 \mathrm{M} \mathrm{NaOH}$ aq.

\section{Measurements}

The infrared spectra were recorded on a Horiba FT720 spectrophotometer. The ${ }^{1} \mathrm{H}$ and ${ }^{13} \mathrm{C}$ NMR spectra were obtained on a JEOL JNM-AL400 spectrometer at ${ }^{1} \mathrm{H}, 400 \mathrm{MHz}$ and ${ }^{13} \mathrm{C}, 100 \mathrm{MHz}$. Number- and weight-average molecular weights $\left(M_{\mathrm{n}}\right.$ and $\left.M_{\mathrm{w}}\right)$ were determined by a gel permeation chromatograph (GPC) on a Hitachi LC-7000 system equipped with a polystyrene gel column (TSKgel GMHHR-M) eluted with tetrahydrofuran (THF) at a flow rate of $1.0 \mathrm{~mL} \mathrm{~min}^{-1}$ calibrated by standard polystyrene samples. The cyclic voltammogram was measured at room temperature in a typical three electrode with a working ( $\mathrm{Pt}$ wire), a reference $(\mathrm{Ag} / \mathrm{AgCl})$, and a counter electrode (Pt spiral) under a nitrogen atmosphere at a sweeping rate of $10 \mathrm{mV} / \mathrm{s}$ (Hokuto Denko HSV-100). A $0.1 \mathrm{M}$ solution of tetrabutylammonium perchlorate in anhydrous acetonitrile was used as an electrolyte. Thermal analysis was performed on a Seiko EXSTAR 6000 TG/DTA 6300 thermal analyzer at a heating rate of $10^{\circ} \mathrm{C} / \mathrm{min}$ for thermogravimetry (TG), differential thermal analysis (DTA), and a Seiko EXSTAR 6000 DSC 6200 at a heating rate of $10^{\circ} \mathrm{C} / \mathrm{min}$ in the temperature range from 25 to $300^{\circ} \mathrm{C}$ for differential scanning calorimetry (DSC) under nitrogen. Disk-like samples with thickness of $600 \mu \mathrm{m}$ were prepared by compression molding. Proton conductivity measurements were performed on the acid form of the disklike samples using a Hioki 3532-80 Chemical impedance meter. An impedance spectrum was recorded from $5 \mathrm{~Hz}$ to $1 \mathrm{MHz}$. The resistance of the sample was taken at the frequency that produced the minimum imaginary response. All the impedance measure- ments were performed at $80^{\circ} \mathrm{C}$ above water with $95 \%$ or $50 \%$ relative humidity $(\mathrm{RH})$.

\section{Calculation}

The density functional theory (DFT) with the threeparameter Becke-style hybrid functionals (B3LYP) was used for calculation of the Mulliken population charges for neutral compounds and the local spin densities for radical cations. Molecular geometries in the neutral sates were optimized under no constraints, and the Fukui functions were calculated as differences in Mulliken charges between the neutral and the radical cation states having the same molecular geometries. The 6-311G(d) basis set was used for the geometry optimization and the calculations of Mulliken charges and spin densities. Radical cations were always treated as open shell systems (uB3LYP). The molecular geometries of radical cations were optimized independently from the neutral molecules prior to the calculations of local spin densities. In addition, the UV/ Vis optical absorption spectra were calculated for monomer (1) and model compounds using the timedependent DFT methods with the B3LYP functional and the $6-311^{++} \mathrm{G}(\mathrm{d}, \mathrm{p})$ basis set. The details for the theoretical prediction of absorption spectra have been reported elsewhere. ${ }^{8}$ All the calculations were performed using the software of Gaussian-03 (Revision C02). ${ }^{11}$

\section{RESULTS AND DISCUSSION}

\section{Cyclic Voltammogram of Monomer 1}

It is important to measure the oxidation-reduction potentials of 1 for the selection of oxidants. The cyclic voltammogram of $\mathbf{1}$ was measured in acetonitrile solution containing $0.1 \mathrm{M}$ tetrabutylammonium perchlorate in a cell equipped with a reference electrode $(\mathrm{Ag} / \mathrm{AgCl})$, a working electrode $(\mathrm{Pt})$, and an auxiliary electrode $(\mathrm{Pt})$. The redox process was observed at the oxidation potential value of $1.6 \mathrm{~V}$ vs SCE (Figure 1). Thus, $\mathrm{FeCl}_{3}$ was selected as the oxidant for oxidative coupling polymerization of $\mathbf{1}$.

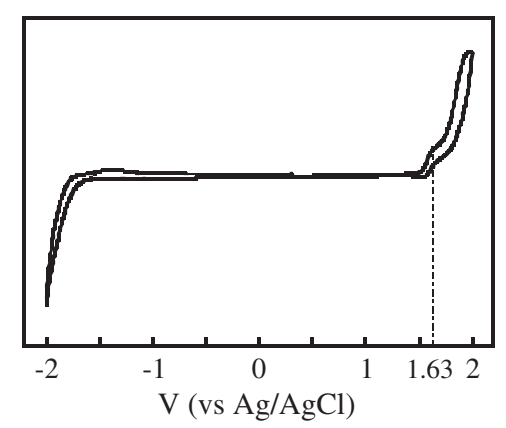

Figure 1. Cyclic voltammogram of monomer 1. 
Table I. Calculated Mulliken charge densities for 1,4-diphenoxybenzene (1) in the neutral state $\left(P^{0}\right)$ and the radical cation state $\left(P^{+}\right)^{\mathrm{a}}$, and calculated spin densities in the radical cation state $\left(\rho^{+}\right)$

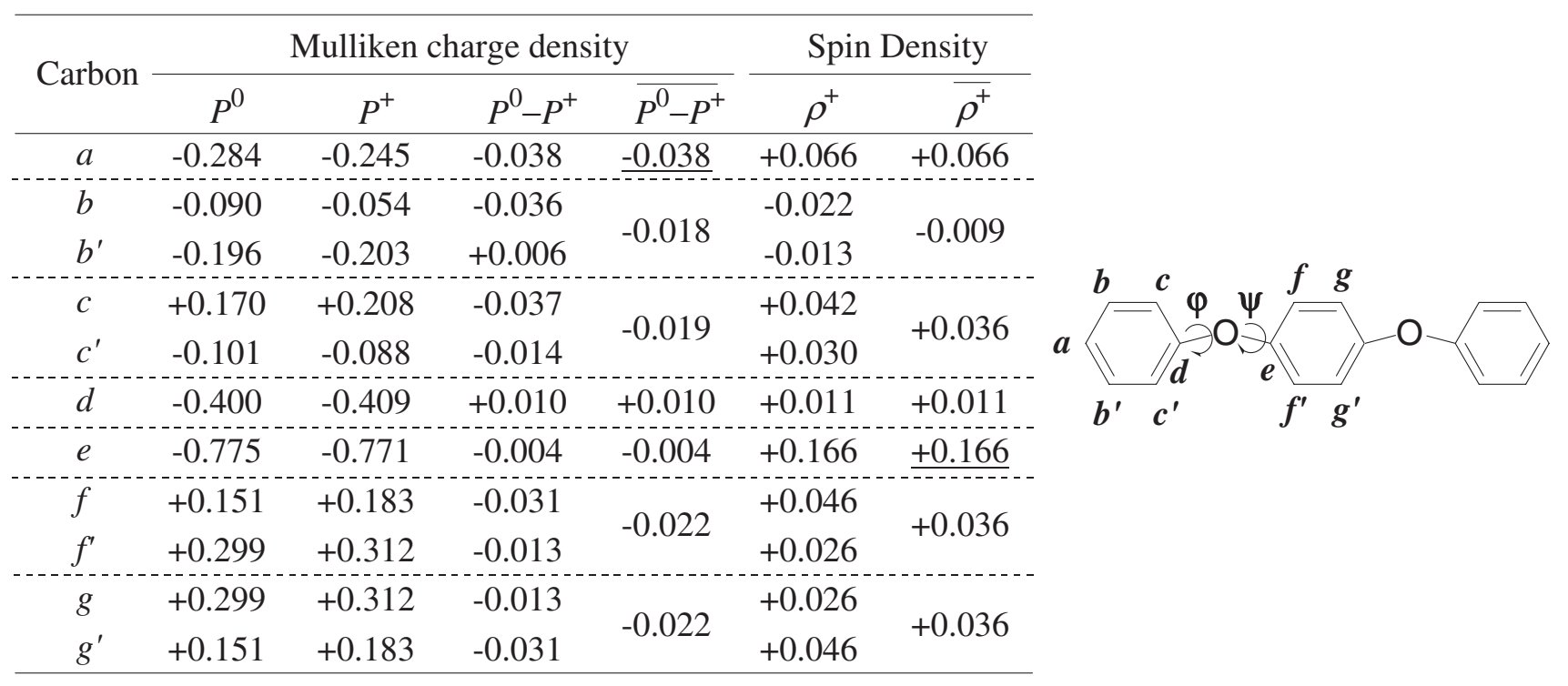

${ }^{a}$ Using the geometry optimized for the neutral state $(\varphi, \psi)=\left(29.5^{\circ}, 52.5^{\circ}\right)$, and the calculated spin densities $\left(\rho^{+}\right)$in the radical cation state using the geometry optimized for the radical cation state; $(\varphi, \psi)=\left(47.0^{\circ}, 17.7^{\circ}\right)$. Averaged values for the geometrically identical carbons are indicated with overbars.

Prior to oxidative polymerization of $\mathbf{1}$, coupling positions were speculated by using MO calculation. The calculated Mulliken charge densities $(P)$ and the Fukui functions $\left(P^{0}-P^{+}\right)$in the neutral state of monomer $\mathbf{1}$ are listed in Table I together with the calculated spin densities in the radical cation state. Although it is not clear whether the polymerization proceeds via free-radical cations or coordinating cations with Lewis acids $\left(\mathrm{FeCl}_{3}\right)$ at the oxygen, the following discussion is based on the assumption that the polymerization proceeds via free-radical cations. The dihedral angles $(\varphi$ and $\psi)$ at the ether linkages in the neutral and the radical cation states for 1 are $\left(29.5^{\circ}, 52.5^{\circ}\right)$ and $\left(47.0^{\circ}, 17.7^{\circ}\right)$, respectively. These values indicate that the latter takes more planar and elongated structure than the former, which may lead to an extension of delocalized unpaired electrons. In the radical cation state of 1 representing the electronic conditions during oxidative coupling under the excess of $\mathrm{FeCl}_{3}$, the largest spin density is located at $e$ position. The positive spin densities located at the outer and the central phenyl rings are +0.131 and +0.476 , respectively. This indicates that the central phenylene ring is more reactive than the outer phenyl rings. We have reported that the spin densities obtained using the TD-DFT calculations can be used to predict the reactive sites in oxidation coupling reactions of aromatic molecules. ${ }^{9,10}$ Hence, the oxidative coupling reactions of 1 should preferentially occur between the central phenylene carbons, giving polyphenylene linkages accompanying with delocalized $\pi$-conjugation.
In contrast, the carbon atoms having higher $\pi$-electron densities should exhibit higher reactivity in sulfonation reaction because it is an electrophillic substitution of aromatic molecules. In this study, the $\pi$ electron densities were estimated by the Fukui function $\left(P^{0}-P^{+}\right)$, which can be calculated as a difference in the Mulliken charge densities for each carbon between the neutral and radical cation states. The $P^{0}$ $P^{+}$values essentially represent the probabilities of the electrons in the highest occupied molecular orbital (HOMO). Contrary to the spin densities in radical cations, a large negative value of $P^{0}-P^{+}$is obtained at $a$ position in the outer phenyl rings of $\mathbf{1}$, which indicates that the carbons at para-position from the ether linkage should be preferentially sulfonated by chlorosulfonic acid.

\section{Synthesis of Polymer 2}

The oxidative coupling polymerization of $\mathbf{1}$ was carried out in nitrobenzene with $\mathrm{FeCl}_{3}$ at $40{ }^{\circ} \mathrm{C}$ for $24 \mathrm{~h}$ (Scheme 1). Polymerization using 4 equivalent of $\mathrm{FeCl}_{3}$ produced polymer 2 with the number-average $\left(M_{\mathrm{n}}\right)$ and weight-average $\left(M_{\mathrm{w}}\right)$ molecular weights of 11,000 and $36,000 \mathrm{Da}$, respectively, calibrated with polystyrene standards.

The characterization of polymer $\mathbf{2}$ was performed by IR and NMR spectroscopy, and elemental analysis. The IR spectrum of polymer $\mathbf{2}$ exhibited characteristic absorptions at 690,1489 and $1593 \mathrm{~cm}^{-1}$ due to the phenyl rings and at $1215 \mathrm{~cm}^{-1}$ due to the C-O-C stretching. The ${ }^{13} \mathrm{C}$ NMR spectra of $\mathbf{1}$ and polymer 


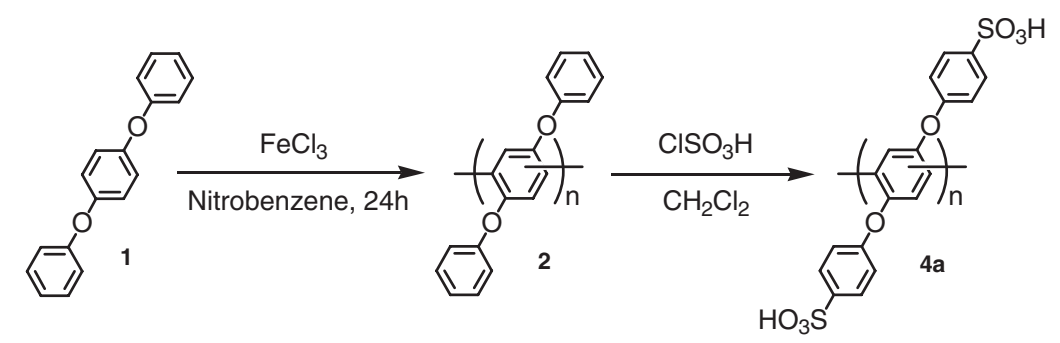

Scheme 1. Oxidative coupling polymerization of monomer 1 and sulfonation of the resulting polymer.

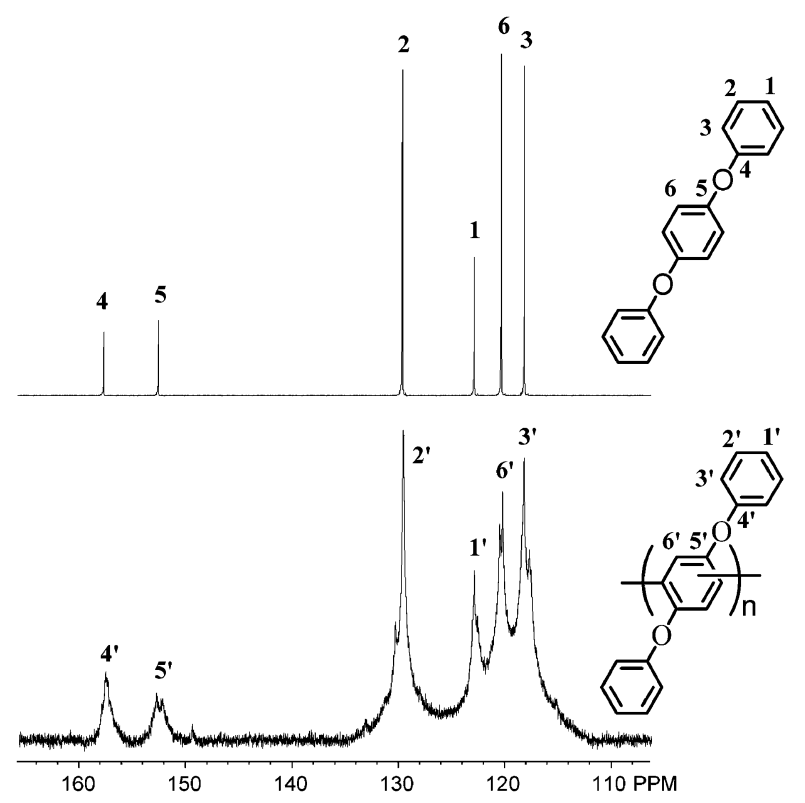

Figure 2. Expanded ${ }^{13} \mathrm{C}$ NMR spectra of $\mathbf{1}$ and polymer $\mathbf{2}$ in DMSO- $d_{6}$.

2 are shown in Figure 2. The ${ }^{13} \mathrm{C}$ NMR signal of polymer $\mathbf{2}$ is very similar to that of monomer $\mathbf{1}$, but it is difficult to determine the coupling positions because ${ }^{13} \mathrm{C}$ peaks of coupling positions are too weak to identify. Thus, to estimate the structure of polymer 2 , a model compound, $p$-phenylenedioxybis(4-benzenesulfonic acid) (3) was prepared by sulfonation of $\mathbf{1}$ because the para position (1) of the phenoxy group in 1 would be the other probable coupling position. The structure of $\mathbf{3}$ was confirmed by IR and NMR spectroscopy and elemental analysis. However, the coupling reaction of position (1) of the phenoxy group in $\mathbf{1}$ cannot be completely excluded because of week ${ }^{13} \mathrm{C}$ peaks of coupling positions.

\section{Synthesis of Polymer $\mathbf{4 a}$}

Sulfonation of polymer 2 was also carried out to show that the para position (1) of the phenoxy group was not involved in the coupling (Scheme 1). Figure 3 shows the ${ }^{13} \mathrm{C}$ NMR spectra of $\mathbf{3}$ and polymer 4a. The $\mathrm{C}-1$ resonance of $122.96 \mathrm{ppm}$ in 1 shifts to $141.57 \mathrm{ppm}$ in $\mathbf{3}$, and the $\mathrm{C}-1$ ' resonance of 123.11

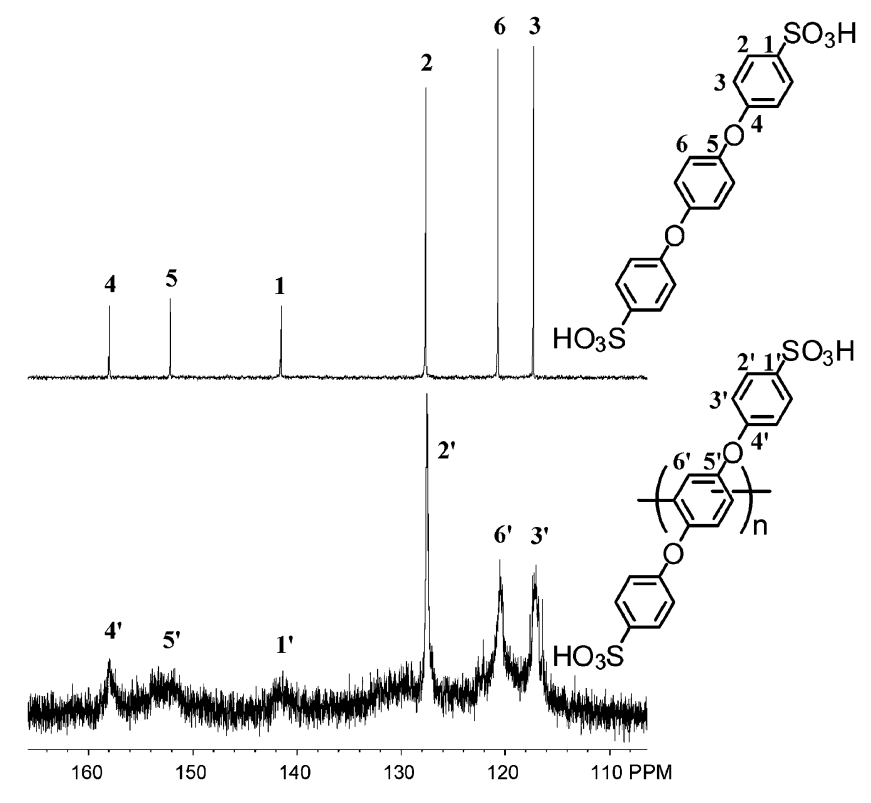

Figure 3. Expanded ${ }^{13} \mathrm{C}$ NMR spectra of $\mathbf{3}$ and polymer $\mathbf{4 a}$ in DMSO- $d_{6}$.

ppm in polymer 2 also shifts to $141.31 \mathrm{ppm}$ in polymer 4a. All other peaks are well assigned to the proposed structure of $\mathbf{3}$ and polymer $\mathbf{4 a}$. These findings indicate the $\mathrm{C}-1$ position in $\mathbf{1}$ is almost intact during the polymerization and is selectively sulfonated by the subsequent treatment with chlorosulfonic acid. These reacted positions are in very good agreement with those predicted by the DFT calculations.

The UV/Vis absorption spectra of monomer $\mathbf{1}$ and polymer $\mathbf{2}$ in chloroform with the concentrations of $5 \times 10^{-5} \mathrm{~mol} / \mathrm{L}$ was measured. The absorption edge $\left(\lambda_{\mathrm{e}}\right)$ of 2 appears at $550 \mathrm{~nm}$, which is much longer wavelengths than $\mathbf{1}$, suggesting the delocalization of $\pi$-electrons ( $\pi$-conjugation) along the polymer main chain (Figure 4). Polymer 2 was soluble in tetrahydrofuran, chloroform and nitrobenzene at room temperature. On the other hand, polymer $\mathbf{4 a}$ was soluble in water and polar aprotic solvents, such as $\mathrm{N}, \mathrm{N}$-dimethylformamide, $N, N$-dimethylacetamide, and dimethyl sulfoxide at room temperature. The thermal properties of polymer 2 were examined by thermogravimetry (TG) and differential scanning calorimetry (DSC). 


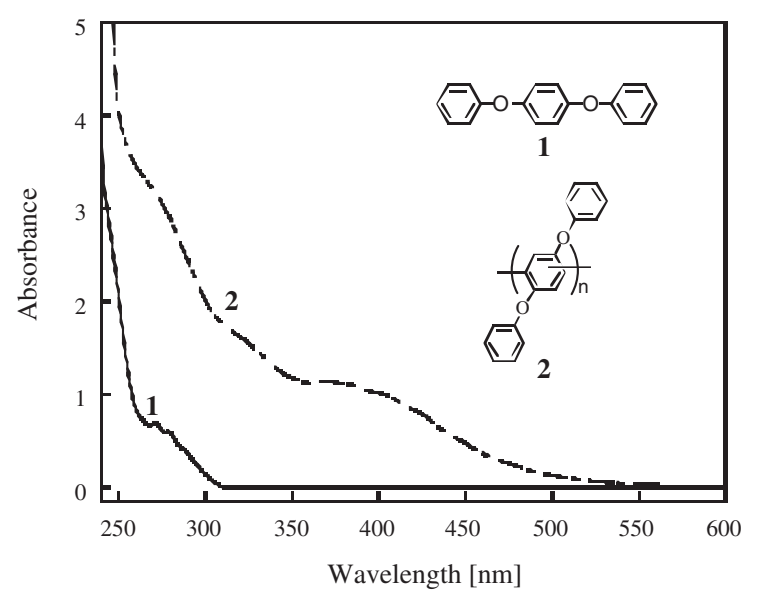

Figure 4. UV/Vis absorption spectra of $\mathbf{1}$ and polymer $\mathbf{2}$ in $\mathrm{CHCl}_{3}$.

Polymer 2 showed an excellent thermal stability, and a $10 \%$ weight loss temperature was $520^{\circ} \mathrm{C}$ under nitrogen. The DSC trace exhibited no endothermic peak and a baseline shift due to the melting point and glass transition, respectively.

\section{Synthesis and Proton Conductivity of Partially Sulfo- nated Polymer $\mathbf{4 b}$ and $\mathbf{4 c}$}

Polymer $\mathbf{2}$ was reacted with chlorosulfonic acid in dichloromethane, affording partially sulfonated polymer $\mathbf{4 b}$ and $\mathbf{4 c}$ with the numbers of sulfonic acid groups in the repeating unit of 0.74 and 0.38 , respectively. The ion-exchange capacities (IEC) of polymer 4b and $4 \mathbf{c}$ were 2.3 and 1.3 mequiv/g, respectively. Since they were difficult to make robust films by casting from polymer solutions, disk-like samples were prepared by compression molding. The proton conductivity of polymer $\mathbf{4 b}$ and $\mathbf{4 c}$ was measured at $80^{\circ} \mathrm{C}$ (Figure 5). The low proton conductivity is observed for polymer $\mathbf{4 c}$ at 50 and $95 \%$ RH. On the other hand, polymer $\mathbf{4 b}$ shows the high proton conductivity of $2 \times 10^{-1} \mathrm{~S} / \mathrm{cm}$ at $95 \% \mathrm{RH}$. This proton conductivity is higher than that of Nafion $\mathrm{N}-115$. The proton conductivity of polymer $\mathbf{4 b}$ at $50 \% \mathrm{RH}$ is also high which is comparable to that of Nafion N-115.

\section{CONCLUSIONS}

A facile method to prepare sulfonated PPs has been developed. Poly(1,4-diphenoxybenzene) 2 with relatively high molecular weights was readily prepared by oxidative coupling polymerization of $\mathbf{1}$ by using $\mathrm{FeCl}_{3}$. The structure of polymer 2 was characterized by NMR and UV/Vis spectroscopy and estimated to consist almost of the coupling on the central phenyl ring of $\mathbf{1}$. Sulfonated polymer $\mathbf{4 b}($ IEC $=2.3)$ showed the comparable proton conductivity to Nafion N-115

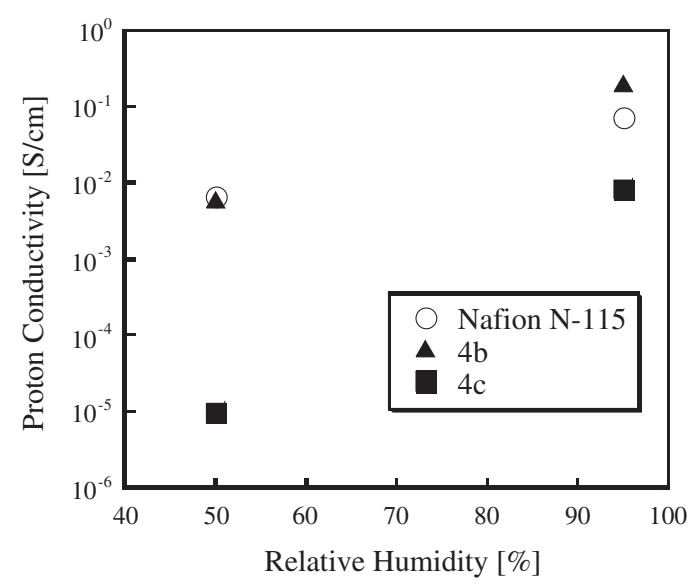

Figure 5. Humidity dependence of the proton conductivity of polymer $\mathbf{4 b}$ and $\mathbf{4 c}$, and Nafion N-115.

and the high conductivity $\left(2 \times 10^{-1} \mathrm{~S} / \mathrm{cm}\right)$ was obtained at $80^{\circ} \mathrm{C}$ and $95 \% \mathrm{RH}$. This synthetic method of PPs will provide a potentially and versatile route.

Acknowledgment. We thank Miss. Hiroko Kobashi at Research Center of Macromolecular Technology, National Institute of Advanced Industrial Science and Technology for taking ${ }^{13} \mathrm{C}$ NMR spectra.

\section{REFERENCES}

1. M. A. Hickner, H. Ghassemi, Y. S. Kim, B. R. Einsla, and J. E. McGrath, Chem. Rev., 104, 4587 (2004).

2. Y. Yin, O. Yamada, K. Tanaka, and K. Okamoto, Polym. J., 38, 197 (2006).

3. T. Kobayashi, M. Rikukawa, K. Sanui, and N. Ogata, Solid State Inonics, 106, 219 (1998).

4. K. Kaneko, S. Aoki, T. Yamawaki, T. Taniguchi, Y. Takeoka, M. Rikukawa, and K. Sanui, Polym. Prepr. Jpn., 53(2), 4770 (2004).

5. C. H. Fujimoto, M. A. Hickner, C. J. Cornelius, and D. A. Loy, Macromolecules, 38, 5010 (2005).

6. M. Ueda, T. Abe, and H. Awano, Macromolecules, 25, 5125 (1992).

7. T. Okada, T. Ogata, and M. Ueda, Macromolecules, 29, 7645 (1996).

8. S. Ando, T. Fujigaya, and M. Ueda, Jpn. J. Appl. Phys., 41(2A), 105 (2002).

9. T. Hayakawa, K. Fukukawa, M. Morishima, K. Takeuchi, M. Asai, S. Ando, and M. Ueda, J. Polym. Sci., Part A: Polym. Chem., 39, 2287 (2001).

10. S. Ando and M. Ueda, Synth. Met., 129, 207 (2002).

11. M. J. Frisch, G. W. Trucks, H. B. Schlegel, G. E. Scuseria, M. A. Robb, J. R. Cheeseman, J. A. Montgomery, Jr., T. Vreven, K. N. Kudin, J. C. Burant, J. M. Millam, S. S. Iyengar, J. Tomasi, V. Barone, B. Mennucci, M. Cossi, G. Scalmani, N. Rega, G. A. Petersson, H. Nakatsuji, M. Hada, M. Ehara, K. Toyota, R. Fukuda, J. Hasegawa, M. Ishida, T. Nakajima, Y. Honda, O. Kitao, H. Nakai, M. Klene, X. Li, J. E. Knox, H. P. Hratchian, J. B. Cross, V. Bakken, C. 
Adamo, J. Jaramillo, R. Gomperts, R. E. Stratmann, O. Yazyev, A. J. Austin, R. Cammi, C. Pomelli, J. W. Ochterski, P. Y. Ayala, K. Morokuma, G. A. Voth, P. Salvador, J. J. Dannenberg, V. G. Zakrzewski, S. Dapprich, A. D. Daniels, M. C. Strain, O. Farkas, D. K. Malick, A. D. Rabuck, K. Raghavachari, J. B. Foresman, J. V. Ortiz, Q.
Cui, A. G. Baboul, S. Clifford, J. Cioslowski, B. B. Stefanov, G. Liu, A. Liashenko, P. Piskorz, I. Komaromi, R. L. Martin, D. J. Fox, T. Keith, M. A. Al-Laham, C. Y. Peng, A. Nanayakkara, M. Challacombe, P. M. W. Gill, B. Johnson, W. Chen, M. W. Wong, C. Gonzalez, and J. A. Pople, Gaussian, Inc., Wallingford CT, 2004. 